\title{
Novel or Consistent Music? - An Electrophysiological Study Investigating Music Use in Advertising
}

\author{
Joydeep Bhattacharya ${ }^{\mathrm{a}, \text {,f,* }}$, Ioanna Zioga ${ }^{\mathrm{a}, \mathrm{b}^{*}}$, Richard Lewis ${ }^{\mathrm{c}, *}$ \\ ${ }^{\text {a }}$ Department of Psychology, Goldsmiths, University of London, London, United Kingdom \\ b School of Biological and Chemical Sciences, Queen Mary, University of London, London, \\ United Kingdom \\ ${ }^{\mathrm{c}}$ NeuroFormed Ltd, London, United Kingdom \\ *All authors contributed equally \\ \#Corresponding author: j.bhattacharya@gold.ac.uk (JB)
}

Author contributions: JB, RL: designed the research; IZ: programmed the experiment, collected and pre-processed the data; JB: analysed the data; JB, IZ and RL: wrote the paper; JB: supervised the whole project.

Acknowledgments: We are thankful to Leo Archutowski for his help with selecting the adverts. The research was partially supported by the Radiocentre, UK. 
We often recognize major brands just by hearing the familiar background music of an advert. When a few bars of Etta James's "I just want to make love to you" comes blasting out of the television, most viewers do not even need to glance at the screen to know that a glistening can of Diet-Coke ${ }^{\circledR}$ is about to be cracked open and poured from a height down the throat of a handsome male labourer titillating the overlooking female office workers with his rippling torso. Why do we recognize this advert so quickly? Since 1996 radio and television adverts for Diet-Coke ${ }^{\circledR}$ have been consistent and strategic in their use of background music. As a direct consequence, the associations between this particular music track and this particular sugar-free soft drink brand has become emblazoned on the very fabric of the consumer brain. Music has become an integral part of the marketing (Treasure, 2011). Yet music is often used inconsistently, changing from campaign to campaign or even taken off completely, seemingly at the whim of some influential decision maker's hunch (Saner, 2016). This study was designed to establish, empirically, the impact of approach to music selection on advertising engagement, as measured by both subjective (i.e. behavioural ratings) and objective (i.e. brain response) means.

Music can induce powerful emotions, communicate complex meaning and influence the commercial success of a product (Graakjær \& Jantzen, 2009). Several studies have investigated the role of music in advertising and its impact on consumption behaviours (Kellaris, Cox, \& Cox, 1993; Knight \& Chapman, 2004; Lewis, Fretwell, \& Ryan, 2011; North \& Hargreaves, 2008; Robinson, Chen, \& Killen, 1998). For example, Kellaris et al. (1993) found that recall and recognition of adverts are improved by the presence of music that can capture the attention only if it is congruent with the message of the advert. Lewis et al. (2011) showed that interesting sounds induce emotional responses which can be used to drive consumers' purchasing behaviour towards specific choices. However, it is not yet known whether adverts that consistently use the same musical backing track over several consecutive 
campaigns result in more or less positive engagement than those that use a variety of different tracks.

Neurophysiological studies have explored the neural responses to a variety of advertising materials (e.g., Bolls, Lang, \& Potter, 2001; Borghini, Astolfi, Vecchiato, Mattia, \& Babiloni, 2014; Dmochowski, Sajda, Dias, \& Parra, 2012; Khushaba et al., 2013; Kong et al., 2012; Kong, Zhao, Hu, Vecchiato, \& Babiloni, 2013; Rothschild, Hyun, Reeves, Thorson, \& Goldstein, 1988; Vecchiato et al., 2014, 2010; Wang, Chang, \& Chuang, 2016; Yang et al., 2015). It has been observed that consumers can change their preferences towards specific products in response to changes to adverts that are not always consciously perceived (Ohme, Reykowska, Wiener, \& Choromanska, 2009). Because participants are unable to report information of which they have no conscious awareness, employing non-invasive brain imaging techniques may reveal information beyond the traditional marketing methods relying on recall tests, self-report measures (Ariely \& Berns, 2010), and when combined with behavioural responses, neurophysiological measures can provide novel understanding into consumer behaviour and commercial success (e.g., Boksem \& Smidts, 2015; Boksem, 2015; Bolls et al., 2001).

Previous neurophysiological research has revealed several candidate signal features in electroencephalogram (EEG) data that can be evaluated to gain an objective understanding of how human brain responses to adverts may vary depending on memory, preference and arousal (e.g., Bolls et al., 2001; Khushaba et al., 2013; Kong et al., 2013, 2012; Rothschild et al., 1988; Vecchiato et al., 2014, 2011, 2010; Yang et al., 2015). For example, increased beta oscillations have been associated with preference for specific movie trailers (Boksem \& Smidts, 2015; Dmochowski et al., 2012; Boksem, 2015). Further, gamma oscillations have been shown to predict population-wide consumer choices, even though the stated preferences did not (Boksem, 2015). These findings suggest that large scale neuronal oscillations, especially at the higher frequency bands, provide unique and valuable information about individual as well as population-wide consumer preferences. 
Although music is an important element in radio, television and cinema advertising, no study has yet examined the neural underpinnings of music use in advertising and its effect on behaviour. The present study addressed this problem by recording participants' EEG and behavioural responses to the presentation of a selection of radio and TV adverts. In order to explore the impact of music use in advertising, we used adverts that made 'strategic' use of music (the same piece of music consistently used as a backing track across consecutive advert campaigns), 'tactical' use of music (the product/brand has been accompanied by different pieces of background music in consecutive campaigns), or no use of music. Further, in order to investigate potential effects of the musical genre, we used existing adverts with classical, modern and retro musical tracks. Participants were asked to rate their liking of and familiarity with the advert, their liking of the music, as well as their assessment of how well the background music fit with that advertised brand. Notably, we kept the ecological validity of the stimuli intact by using already existing adverts, without manipulating the background music or the video.

In summary, the primary aim of the present study was to investigate the impact of music use (strategic or tactical) or its absence in advertisements on both behavioural responses and large scale brain responses, and compare them between two types of media, TV and radio. A tertiary aim of our study was to investigate the potential impact of musical genre (classical, modern, or retro music) on engagement with radio and TV advertisements. Our first prediction was that adverts using music strategically would be perceived as more familiar and would thus be liked more than adverts that used music tactically or not at all. Our second prediction was that effective use of music in adverts would result in increased beta and gamma oscillations in frontal areas of the brain, which is indicative of increased preference and positive engagement.

\section{METHODS}

The experiment used a $2 \times 3$ within-subjects design with two factors: media (two levels: TV, and radio), music (three levels: strategic music, tactical music, and no music). 


\section{Participants}

Sixteen ( 8 female) neurologically healthy human adult volunteers aged between 18 to 53 years old $(M=35.94, S D=11.90$ years $)$ were recruited for this experiment. All participants were native English speakers, had self-reported normal hearing, normal or corrected-to-normal vision, and received a fixed cash incentive for their participation. They provided written informed consent before the experiment began and were appropriately debriefed at the end. The experimental protocol was approved by the Local Ethics Committee at Goldsmiths.

\section{Stimuli}

A variety of existing radio and television adverts were selected for this study. For adverts belonging to each media (radio or television), there were three categories: (i) adverts with strategic music (same piece of music was paired with the advert across consecutive campaigns), (ii) adverts with tactical music (different pieces of music were paired with the advert across consecutive campaigns), and (iii) adverts with no background music. Therefore, it seems likely that participants would have been exposed to adverts with strategic music at some point in the past. Note that the use of music here is strategic (or tactical) from the perspective of the brand owners, indicating an awareness of the benefits from being consistent in the pairing of music and brand attributes rather than changing tactics (i.e. musical pairing) with every new campaign. We attempted to match the adverts, in terms of advertised product, between radio and TV adverts. Further, for adverts with strategic or tactical music, we ensured three genres of music were equally well represented: classical, modern and retro. There were three adverts for each musical genre for each media and approach to musical pairing, plus nine adverts for each media without any music. So altogether we presented 27 radio adverts ( 9 with strategic music, 9 with tactical music, and 9 without any music) and 27 TV adverts (same music use combinations as radio adverts). Table 1 includes the list of adverts presented in our study. 
All adverts were presented only once to limit the total duration of the experiment and so that participants could concentrate fully throughout.

\section{Procedure}

On arrival at the lab, participants were provided detailed written and verbal instructions about the experimental procedure. Subsequently, the EEG cap and electrodes were placed; participants sat in a quiet, dimly lit and electrically-shielded room. Adverts were presented on a computer monitor and two external speakers were used for the audio; the speaker volume was kept constant across participants and for the entire duration of the experiment. At the end of each advert, participants were instructed to rate the following: (i) their liking of the advert, (ii) their familiarity with the advert, (iii) their liking of the background music, and (iv) their assessment of how well the background music fit with the featured brand. The first response was made on a two-point scale (1: dislike, 2: like) and the latter three responses were made on a four-point scale (higher values suggesting more certain and stronger subjective response to given question). The third and fourth (music-related) responses were not required for the adverts without music. At the end of the whole experiment, participants were briefly interviewed in order to gain a more textured understanding of their engagement levels and attitudes towards the adverts. Presentation of adverts and behavioural ratings were recorded by custom made scripts using Cogent 2000 Toolbox (www.vislab.ucl.ac.uk/cogent.php) based on MATLAB ver. 7.12.0 (The MathWorks, Inc., Natick, MA, 2011).

\section{EEG Recording}

Thirty-two channel EEG signals were recorded by active scalp electrodes placed according to the extended 10-20 electrode placement system (Jasper, 1958) and amplified by a BioSemi ActiveTwo® amplifier (www.biosemi.com). The vertical and horizontal EOGs were recorded in a bipolar fashion to monitor eye-blinks and horizontal eye-movements, respectively. The 
EEG recording used a sampling frequency of $512 \mathrm{~Hz}$ and the signals were band-pass filtered between 0.16 and $100 \mathrm{~Hz}$.

\section{EEG Preprocessing}

EEG signals were algebraically re-referenced to the average of the right and left earlobe electrodes (Essl \& Rappelsberger, 1998). A high-pass filter at $0.5 \mathrm{~Hz}$ was applied to remove slow baseline drifts and a notch filter at $50 \mathrm{~Hz}$ with a 2-Hz bandwidth was applied to remove line noise. Independent component analysis (ICA) using the MATLAB based EEGLAB Toolbox (Delorme \& Makeig, 2004) was applied to the EEG data to remove large blink-related artifacts. Then, the ICA-cleaned EEG data was visually inspected for identification and subsequent removal of any remaining artifacts.

\section{EEG Processing}

EEG signals were analyzed in terms of the constituent oscillatory components, which essentially involves splitting up the signal from each electrode into different frequency bands. We computed the periodogram by the Welch method (Welch, 1967), by using a two-second long Hanning window with a $1 \mathrm{~s}$ overlap. The periodogram was estimated for each scalp electrode and condition for each participant. Spectral power was subsequently averaged in each of the classical EEG frequency bands: delta $(<4 \mathrm{~Hz})$, theta $(4-8 \mathrm{~Hz})$, alpha $(8-13 \mathrm{~Hz})$, beta $(13-$ $30 \mathrm{~Hz}$ ) and gamma (30-48 Hz). The EEG spectral power obtained this way provides an overall representation of neuronal oscillations for the entire duration of each advert, i.e. it does not contain any temporal information.

In order to capture the temporal dynamics of neuronal oscillations, we applied amplitude envelope analysis (Bhattacharya \& Petsche, 2001). Briefly, an EEG signal, $\{x(t)\}$, was first band-pass filtered in a chosen frequency band to produce $\left\{x_{\mathrm{f}}(t)\right\}$. Next we formed the analytic signal, $x_{a n}(t)=x_{f}(t)+j x_{H T}(t)=x_{f}(t)+j \frac{1}{\pi} \int_{-\infty}^{\infty} \frac{x_{f}(t)}{t-\tau} d \tau$, where $\left\{X{ }_{H T}(t)\right\}$ is the Hilbert Transform of $\{\mathrm{Xf}(t)\}$. As $\left\{X_{a n}(t)\right\}$ is a complex quantity, we could represent it in polar fashion: 
$x_{a n}(t)=E(t) e^{j \emptyset(t)}$ where $E(t)=\sqrt{x_{f}^{2}(t)+x_{H T}^{2}(t)}$ and $\emptyset(t)=\tan ^{-1}\left(\frac{x_{H T}(t)}{x_{f}(t)}\right) . E(t)$ is the instantaneous amplitude or envelope and $\phi(t)$ is the instantaneous phase of the band-pass filtered signal. The time profile of $E(t)$ provides the time varying nature of the strength of the chosen neuronal oscillations (Cohen, 1995).

Our final EEG measure of frontal asymmetry was based on Davidson's influential approach/withdrawal motivational model of emotion (Davidson, 2004): left frontal activity indicates a tendency to approach or engage with a stimulus, whereas right frontal activity indicates a tendency to withdraw or disengage from a stimulus. As frontal asymmetry is mostly reflected by the alpha band oscillations (Smith et al., 2017), we calculated the frontal asymmetry index based on alpha band power over frontal electrodes. The (log transformed) alpha power over left frontal electrode regions (Fp1, AF3, F7, F3, FC1, FC5) was subtracted from the alpha power over right frontal electrode regions (Fp2, AF4, F8, F4, FC2, FC6). The strength of alpha oscillations as measured on the scalp is inversely correlated to the cortical excitations, therefore positive frontal asymmetry index suggests more left frontal activations.

\section{Statistical Analysis}

Mean ratings for advert preference and familiarity, music preference, and fitness of background music to the advertised brand were calculated for radio and TV adverts for each participant. For the first two ratings, a 2x3 within-subjects factorial analysis of variance (ANOVA) with factors media (two levels: radio and TV) and music (three levels: strategic music, tactical music and no music) was performed. For the last two ratings, a $2 \times 2$ within-subjects ANOVA with factors media (two levels: radio and TV) and music (two levels: strategic music and tactical music) was carried out. Further analysis to investigate the effect of musical genre used a $2 \times 3$ within-subjects factorial ANOVA with factors music (strategic and tactical) and genre (classical, modern and retro) on all four ratings.

As our EEG predictions were made for the beta and gamma oscillations, we first performed statistical comparison for the beta and gamma frequency bands separately at global level, i.e. 
spectral power averaged over the 32 electrodes. Global spectral power was log transformed to reduce the variance before the analysis by within-subjects factorial ANOVA as earlier and by suitable post hoc contrasts. Subsequently, we investigated the distribution of spectral power over the scalp in order to identify the electrode regions showing the maximum effect size.

Statistical analysis was performed by IBM SPSS ${ }^{\circ}$ Software Package Ver 23. All $p$ values were reported after applying Greenhouse-Geisser correction.

\section{RESULTS}

\section{Behavioural Findings}

\section{Advert preference}

First, we analysed the subjective responses to the preference or liking rating on the adverts (Fig. 1a). We performed a within-subjects $2 \times 3$ factorial ANOVA with two factors, media (radio and TV) and music (strategic, tactic and no music). There was a main effect of music $(F(2,30)$ $=5.08, p=.013$, partial eta squared $\left.\eta^{2}=.25\right)$. Post-hoc contrasts revealed that both musical adverts, strategic and tactical, were liked more than the adverts without music (strategic vs no music: $F(1,15)=7.35, p=.016$; tactical vs no music: $F(1,15)=8.89, p=.009)$ but there was no difference between preference ratings between strategic and tactical adverts $(F(1,15)=.33$, $p>.5$, n.s.). The main effect of media was not significant $(F(1,15)=1.57, p=.23)$. The interaction between media and music was not significant $(F(2,30)=1.34, p=.28$, n.s. $)$.

\section{$<<$ Insert Figure 1 here $>>$}

\section{Advert familiarity}

Next, we analysed the responses to the familiarity rating of the adverts and Fig. 1b shows the average responses across conditions. A $2 \times 3$ within-subjects ANOVA revealed a marginal interaction between media and music $\left(F(2,30)=2.87, p=.08, \eta^{2}=.16\right)$, and post hoc contrast 
revealed a trend towards a larger difference between adverts with strategic music and adverts with no music for TV adverts as compared to radio adverts $(F(1,15)=2.17, p=.05)$. Further, we observed a main effect of music $\left(F(2,30)=32.07, p<.001, \eta^{2}=.68\right)$. Post-hoc contrasts revealed that adverts with strategic music were perceived as more familiar than adverts with tactical music $(F(1,15)=33.64, p<.001)$ and adverts without music $(F(1,15)=42.37, p<$ $.001)$, but no significant differences were observed between adverts with tactical music and adverts without music $(F(1,15)=2.7, p=.12)$. There was no significant main effect of media $(F(1,15)=.83, p>.3$, n.s. $)$.

\section{Preference ratings for background music}

Mean preference ratings for the music across the four conditions is shown in Fig. 1c. A withinsubjects 2x2 factorial ANOVA revealed a main effect of media $\left(F(1,15)=11.71, p=.004, \eta^{2}\right.$ $=.44)$; music in the TV ads was liked more $(M=3.03)$ than music in the radio ads $(M=2.93)$. There was also a main effect of music $\left(F(1,15)=4.67, p=.047, \eta^{2}=.24\right)$; strategic music was liked more $(M=3.04)$ than tactical music $(M=2.93)$. However, the interaction between media and music was not significant $(F(1,15)=.05, p>.8$, n.s. $)$.

\section{Goodness of fit ratings for brand and music}

Fig. 1d shows the mean goodness-of-fit ratings of music to the advertised brands. A withinsubjects 2x2 ANOVA revealed a significant main effect of media $(F(1,15)=7.42, p=.016$, $\left.\eta^{2}=.33\right)$; musical pieces for the TV adverts $(M=2.99)$ were rated as a better fit to the product brand than musical pieces for the radio adverts $(M=2.89)$. Further, there was also a main effect of music $\left(F(1,15)=6.44, p=.023, \eta^{2}=.30\right)$ : as compared to tactically used music $(M=2.84)$, strategic music $(M=3.04)$ was rated significantly higher in terms of how well it fit the product brand. There was no significant interaction between media and music $(F(1,15)=0.58, p>.4$, n.s.). 


\section{High frequency correlates of processing adverts}

Mean spectral power at the global level (average power across all electrodes) for the beta (13$30 \mathrm{~Hz})$ and gamma $(30-48 \mathrm{~Hz})$ frequency band are shown in Fig. 2(a-d) and Fig. 2(e-h), respectively.

\section{$<$ Insert Figure 2 >>}

For the beta power, adverts with strategic music were associated with the highest average beta band power at the whole brain level; a one-way within-subjects ANOVA revealed a marginal effect $\left(F(2,30)=2.89, p=.08, \eta^{2}=.16\right)$. Post hoc comparisons suggest a trend towards larger beta power for strategic adverts as compared to adverts with tactical music $(F(1,15)=3.84, p$ $=.07)$ and without music $(F(1,15)=3.53, p=.08)$. Larger beta band responses could be observed for strategic adverts over fronto-central and frontal electrode regions in both hemispheres. Repeating the similar analysis on the beta power at the global level for TV adverts (Fig. 2c, d), we did not find any statistically significant difference between the three types of adverts $(F(2,30)=.70, p=.48$, n.s.). Pairwise contrasts revealed no difference between strategic adverts and tactical adverts $(F(1,15)=.20, p=.66)$ and no music adverts $(F(1,15)=$ $.37, p=.55)$.

Fig. 2e shows the mean gamma band power at the whole brain level for the three types of radio adverts. Like the beta band analysis, the gamma band power averaged over the whole brain was highest for the adverts with strategic music; a one-way ANOVA revealed a significant effect $\left(F(2,30)=3.66, p=.04, \eta^{2}=.20\right)$. Post hoc tests revealed that the adverts with strategic music was associated with higher gamma power at the whole brain level than both adverts with tactical music $(F(2,30)=4.62, p=.04)$ and no music $(F(2,30)=4.75, p=.046)$. The scalp map of the adverts with strategic music (Fig. 2f) showed a robust fronto-temporal distribution with a slight dominance over the left frontal brain region. Repeating the similar analysis on the 
gamma power at the global level for TV adverts (Fig. 2f), we did not find any statistically significant difference between the three types of adverts $(F(2,30)=.42, p=.66)$. Therefore, the impact of background music was much larger for radio adverts compared to TV adverts, and it was the strategic usage of the music that made the difference.

$<<$ Insert Figure $3>>$

\section{Timing of musical impact on engagement}

In order to study how high frequency brain oscillations vary with the whole time course of the presented adverts, we estimated the time varying nature of the beta and gamma oscillations by applying amplitude envelope analysis (see Methods) over frontal electrodes bilaterally (AF3/4, F7/8, F3/4, FC1/2, FC5/6). Fig. 3 shows the temporal profile of beta-gamma power over frontal regions over the entire duration of adverts for both radio (upper panel) and TV (lower), respectively. On average, we observed a better separation in the dynamical profiles of high frequency oscillations between strategic and tactical music for radio adverts, and this separation was less conspicious for TV adverts. In order to statistically compare strategic vs tactical adverts separately for radio or TV, we first performed running two-tailed $t$-test and then considered a temporal window of $100 \mathrm{~ms}$ significant if majority of the time points within that specific window have met the statistical criterion $(p<.05)$. This is in line with previous studies (Molholm et al., 2002; Shams et al., 2005) suggesting that this approach is a suitable alternative to Bonferroni procedure for multiple comparison which tends to increase the likelihood of Type II errors. After performing this test, we revealed several long epochs showing significant differences between strategic and tactical adverts only for radio. Interestingly, across both media, strategic adverts was associated with higher spectral power than tactical adverts almost immediately after the onset of adverts. This altogether demonstrates the impact of strategic music was much more robust and temporally sustained for radio adverts than TV adverts. 
As found earlier, a clear impact of music usage at the whole brain level was found at the high frequency beta and gamma bands, and both frequency bands suggest a higher degree of cortical activity or excitation associated with strategic music adverts. If these higher neural activities are indeed robust, one should also expect to observe some trend in another frequency band. This was indeed confirmed by Fig. 4a showing the spectral power differences in the alpha band $(8-12 \mathrm{~Hz})$ between adverts with strategic music and adverts with tactical music. For radio adverts, we observed only a trend towards an increase of neuronal activities (i.e. lower alpha power) associated with the strategic music adverts, but this trend was not observed for TV adverts. This altogether confirms that the impact of strategic music could potentially be more important for the radio adverts. Note that we did not observe any clear pattern of results in other lower frequency bands (theta and delta).

\section{Approach/avoidance metric}

Next we calculated the frontal alpha asymmetry (see Methods) and the results are shown in Fig. 4b for both radio (left panel) and TV (right panel) adverts. As the alpha power is inversely associated with cortical excitations, high values indicate that left frontal activations are greater than right frontal activations, which is usually associated with positive emotional responses. Conversely, low values would indicate greater right than left frontal activations, indicative of negative emotional responses. For radio adverts, we observed a systematic decrease in this cortical asymmetry index from strategic to tactical to adverts without any music. A paired sample $t$-test revealed a significant difference between strategic and tactical radio adverts in this regard $(t(15)=2.32, p=.035)$, but no difference for the same comparison for TV adverts $(t(15)=-1.40, p=.18)$. This demonstrates a left frontal dominance for radio adverts with strategic music, thereby suggesting potentially positive emotional engagement with the radio adverts that employed music strategically.

\section{$<<$ Insert Figure $5>>$}


Our final analysis was related to the secondary aim of exploring the potential impact of musical genre use in advertising. The mean ratings of the four behavioural responses for each of three musical genre are shown in Fig. 5a. A 2x3 within-subjects factorial ANOVA with factors music (strategic, tactical) and genre (classical, modern and retro) was performed separately on all four responses. The interaction between music and genre was significant $(F(2,14)=5.97, p=$ $.013)$, but there was no main effect of genre $(p=.43)$. For classical music in radio adverts, higher liking ratings of music were observed for strategic than tactical use $(t(14)=3.65, p=$ .002). Such effects were not observed for modern or retro genre $(p>.4)$. For the liking ratings for radio adverts, there was a main effect of music as expected $(F(1,15)=5.99, p=.027)$. In summary, we observed a strong and consistent impact of classical genre when used strategically. Fig. 5b shows the gamma band power for the three musical genres included in our study. Confirming the behavioural findings, we observed a robust and significant $(p<.01)$ increase of gamma power associated with classical music but only when used strategically, and furthermore this effect was more prominent for radio adverts.

\section{DISCUSSION}

This study investigated the impact of music use on subjective ratings and brain oscillatory responses indicative of positive engagement during the processing of radio and TV adverts. The main objective of this study was to generate empirical evidence that might be helpful in guiding best practices regarding the use of music in advertising. Our findings suggest that particularly for audio only advertising such as in adverts typically encountered on the radio and in podcasts, strategic use of music (consistent use of the same distinctive piece of music across consecutive campaigns) enables ads to make a greater impact on consumers than when used tactically (changing music across campaigns).

Our primary hypotheses regarding participants' subjective behavioural responses were that advertising campaigns in which music was employed strategically would be deemed more 
familiar and better liked than ads employing music tactically and are supported by the results. Not only did strategic use of music lead to higher ratings for ad familiarity and liking, but it also led to higher ratings for how well the music was considered to "fit" the brands compared to tactical music use. These findings are in line with previous literature related to the association between exposure and preference (e.g., Kunst-Wilson \& Zajonc, 1980; Monahan, Murphy \& Zajonc, 2000; Murphy, Monahan \& Zajonc, 1995; Szpunar, Schellenberg \& Pliner, 2004; Zajonc, 1968). For example, Szpunar et al. (2004) found that after incidental listening of music, liking ratings were higher for music that was heard more often in the exposure phase. This increase in liking might happen even without conscious recognition of the stimulus (Zajonc, 1980). Moreover, strategic use of music was specifically associated with a better fit to the advertised brands. Notably, previous empirical research has shown that when there is a good fit between music and advert a strong emotional response is evoked by the advertisement (Morris \& Boone, 1998; Rossolatos, 2012).

As predicted by our second hypothesis, the music usage was significantly associated with high frequency (beta and gamma) neural oscillations in frontal brain regions. Specifically, we found that adverts with strategic music were associated with the highest beta band power compared to adverts with tactical music, especially in fronto-central and frontal bilateral sites. In addition, strategic adverts showed a robust left fronto-temporal distribution in the gamma band. Similar left hemispheric dominance in the gamma band was earlier observed in participants watching adverts that were considered enjoyable (Vecchiato et al., 2010). Previous studies (Cohen, Elger, \& Ranganath, 2007; HajiHosseini, Rodríguez-Fornells, \& MarcoPallarés, 2012; Marco-Pallares et al., 2008) also suggest that beta-gamma oscillatory activity is an important neural signature of reward-related networks. Taken together, we propose that our findings of enhanced frontal high frequency oscillations reflect an enhanced engagement as an outcome of the positive and rewarding evaluation process - during the processing of adverts in which music is used strategically. Therefore, we argue that this effect might subsequently influence goal-directed behaviour, thereby potentially increasing the likelihood of advertisement effectiveness. Recent studies also suggest the role of frontal and temporal 
beta-gamma oscillations in enhanced auditory memory maintenance and decision-making (Leiberg, Lutzenberger, \& Kaiser, 2006; Onton, Delorme, \& Makeig, 2005). Further, a recent study by Boksem and Smidts (2015) has found that beta and gamma oscillations are positively correlated with adverts preference. We suggest that the strategic use of music, especially in radio adverts, leads to greater familiarity and engagement, which in turn causes them to be better liked and easier to retain in memory, thus making people more positively disposed towards the advertised brand or product.

Investigating the time course of the impact of music in adverts, we found interesting and robust differences in the high frequency (beta-gamma) power between the types of adverts. Specifically, the differences between strategic and tactical adverts were more robust and sustained for radio than TV. Presumably there is so much visual information to pay attention to in the TV adverts that the impact of music on engagement is somewhat diminished after its initial impact. In the absence of visual input this effect is sustained during exposure to radio adverts with strategic music adverts inducing a consistent improvement in engagement over tactical music ads throughout their duration. Interestingly, in the exit interviews at the end of our experiment, many participants claimed that they 'instantly recognize' the brand upon hearing the first few bars of the consistently used music alone. The rapid recognition of the brain induced by the music could be considered a crucial feature of an advert in the age of information overload. This was potentially reflected by the very early difference (within first $2 \mathrm{sec}$ from the onset of adverts) we observed, though over a narrow time window and more conspiciously for TV adverts, in the time profiles of strategic vs tactical adverts. This provides an important link between neural evidence and phenomenological experience.

We also observed that the alpha band power was lower (i.e. indicative of increased brain activity, see below) for radio adverts compared to TV adverts, and in adverts where music was used strategically. Alpha power computed at the scalp level is inversely correlated with cortical excitation (Klimesch, 2012; Palva \& Palva, 2007; Sauseng, Klimesch, Gerloff, \& Hummel, 2009). Although this increase of neuronal activities during the processing of strategic radio adverts was not statistically significant, this trend suggests towards a higher emotional 
engagement with the strategic radio adverts. Further analysis on frontal asymmetry revealed that left frontal asymmetry based on alpha band power was higher for radio adverts with strategic music, compared to TV adverts. The neural correlates of this frontal asymmetry activation have been previously associated with positive emotions in the left frontal brain sites and with negative emotions in the right frontal sites (Davidson, 2004; Ohme, Reykowska, Wiener, \& Choromanska, 2009; Solnais, Andreu-Perez, Sánchez-Fernández, \& Andréu-Abela, 2013; Vecchiato et al., 2011, 2014). These findings demonstrate a greater left frontal dominance for radio adverts that use music strategically, thus suggesting a larger positive emotional engagement.

A secondary goal of our study was to investigate the potential impact of music genre (classical, modern and retro) on the processing of radio and TV adverts. Participants gave higher preference ratings for classical music when it was used strategically compared to tactically, in both types of media, whereas this effect was not observed for modern or retro music. This is in line with the reported wide preference for classical music over other more popular musical genres, such as jazz, rock and hip hop (Savage, 2006). The neural underpinnings of these stated preferences manifested as an increase in gamma power for classical music only when used strategically, an effect that was more prominent for radio adverts compared to TV adverts.

Let us offer a few practical remarks and limitations. First, all stimuli in our study were existing adverts for well-known products. We used a wide variety of recent and older campaigns. This has added to the study's ecological validity, but it was not possible to match the strategic and tactical adverts in terms of the year when they were featured. Therefore, any causal link between the use of consistent music and enhanced adverts' familiarity could not be made. However, we do like to note here that all adverts were presented only once within the experiment, so any reported differences on familiarity is likely to reflect the impact of the existing campaign. Second, we categorized the background music into genre, but there were other variables like lyrics, familiarity, musical complexity could differ between the musical excerpts. Third, we primarily looked at aggregate results, i.e., averaging over multiple adverts 
and over the entire temporal window of the adverts. Although we did provide statistical analysis to reveal robust differences, variations across the adverts could have been captured better by correlating behavioural responses to adverts with EEG responses at individual advert level.

In conclusion, we showed that the approach to selecting background music for adverts can have a powerful influence on subjective advert preference, objective advert engagement, and therefore overall advertising effectiveness. Furthermore, we have revealed that a strategic approach to the use of background music, i.e. consistent use of the same track over several campaigns, is more impactful than tactically used music or no music at all. Further, the elevation in engagement is both rapid and persistent in radio adverts. We would suggest, on the basis of these findings, that the most effective approach to constructing advertising assets so as to maximise the promotion of brand preference and engagement, is to carefully select the backing track right from the outset and then stick to it over consecutive campaigns. That way the brand can become synonymous with that particular piece of music. In this way a well selected track can become the backbone of radio and television advertising, by allowing novel creative campaigns to build on previous brand impressions by using music as the common thread. 
Ariely, D., \& Berns, G. S. (2010) Neuromarketing: the hope and hype of neuroimaging in business. Nature Reviews Neuroscience 11, 284-292.

Bhattacharya, J., \& Petsche, H. (2001). Universality in the brain while listening to music. Proceedings. Biological Sciences / The Royal Society, 268(1484), 2423-2433.

Boksem, M. (2015). Can brain responses to movie trailers predict success? RSM Discovery Management Knowledge, 22(2), 5-7.

Boksem, M. A. S., \& Smidts, A. (2015). Brain Responses to Movie Trailers Predict Individual Preferences for Movies and Their Population-Wide Commercial Success. Journal of Marketing Research, 52(4), 482-492.

Bolls, P. D., Lang, a., \& Potter, R. F. (2001). The Effects of Message Valence and Listener Arousal on Attention, Memory, and Facial Muscular Responses to Radio Advertisements. Communication Research, 28(5), 627-651.

Borghini, G., Astolfi, L., Vecchiato, G., Mattia, D., \& Babiloni, F. (2014). Measuring neurophysiological signals in aircraft pilots and car drivers for the assessment of mental workload, fatigue and drowsiness. Neuroscience and Biobehavioral Reviews, 44, 58-75.

Cohen, L. (1995) Time-Frequency Analysis. Prentice Hall: New Jersey.

Cohen, M. X., Elger, C. E., \& Ranganath, C. (2007). Reward expectation modulates feedback-related negativity and EEG spectra. NeuroImage, 35(2), 968-78.

Davidson, R. J. (2004). What does the prefrontal cortex "do" in affect: perspectives on frontal EEG asymmetry research. Biological Psychology, 67(1-2), 219-234.

Delorme, a, \& Makeig, S. (2004). EEGLAB : an open source toolbox for analysis of singletrial EEG dynamics including independent component analysis. Journal of Neuroscience Methods 134, 9-21.

Dmochowski, J. P., Sajda, P., Dias, J., \& Parra, L. C. (2012). Correlated components of ongoing EEG point to emotionally laden attention - A possible marker of engagement? 
Frontiers in Human Neuroscience, 6(May), 1-9.

Essl, M., \& Rappelsberger, P. (1998). EEG cohererence and reference signals: Experimental results and mathematical explanations. Medical and Biological Engineering and Computing, 36(4), 399-406.

Graakjær, N. J., \& Jantzen, C. (2009). Producing corporate sounds. In Music in Advertising: Commercial Sounds in Media Communication \& Other Settings. Edited by N.J. Graakjaer, \& C. Jantzen, Aalborg University Press, pp. 259-274.

HajiHosseini, A., Rodríguez-Fornells, A., \& Marco-Pallarés, J. (2012). The role of betagamma oscillations in unexpected rewards processing. NeuroImage, 60(3), 1678-1685.

Kellaris, J. J., Cox, A. D., Cox, D., \& Cox, D. (1993). Effect on of Ad Background Processing : Contingency Explanation. Journal of Marketing, 57(4), 114-125.

Khushaba, R. N., Wise, C., Kodagoda, S., Louviere, J., Kahn, B. E., \& Townsend, C. (2013). Consumer neuroscience: Assessing the brain response to marketing stimuli using electroencephalogram (EEG) and eye tracking. Expert Systems with Applications, 40(9), $3803-3812$.

Klimesch, W. (2012). Alpha-band oscillations, attention, and controlled access to stored information. Trends in Cognitive Sciences, 16(12), 606-617.

Knight, J., \& Chapman, S. (2004). "A phony way to show sincerity, as we all well know”: tobacco industry lobbying against tobacco control in Hong Kong. Tobacco Control, 13 (Suppl 2), ii13-ii21.

Kong, W., Zhao, X., Hu, S., Vecchiato, G., \& Babiloni, F. (2013). Electronic evaluation for video commercials by impression index. Cognitive Neurodynamics, 7(6), 531-535.

Kong, W., Zhao, X., Hu, S., Zhang, J., Dai, G., Vecchiato, G., \& Babiloni, F. (2012). The study of memorization index based on W-GFP during the observation of TV commercials. 2012 International Conference on Systems and Informatics (ICSAI2012), (September 2015), 2198-2202. 
Kunst-wilson, W. R., \& Zajonc, R. B. (1978). Affective discrimination of stimuli that cannot be recognized. Science, 207(4430), 557-558.

Leiberg, S., Lutzenberger, W., \& Kaiser, J. (2006). Effects of memory load on cortical oscillatory activity during auditory pattern working memory. Brain Research, 1120(1), $131-140$.

Lewis, C., Fretwell, C., \& Ryan, J. (2011). An Empirical Study of Emotional Response to Sounds in Advertising. American Journal of Management, 12(1), 80-91.

Marco-Pallares, J., Cucurell, D., Cunillera, T., García, R., Andrés-Pueyo, A., Münte, T. F., \& Rodríguez-Fornells, A. (2008). Human oscillatory activity associated to reward processing in a gambling task. Neuropsychologia, 46(1), 241-248.

Molholm S., Ritter W., Murray M. M., Javitt D. C., Schroeder C. E., \& Foxe J. J. (2002). Multisensory auditory-visual interactions during early sensory processing in humans: a high density electrical mapping study. Cognitive Brain Research, 14(1), 115-128.

Monahan, J. L., Murphy, S. T., \& Zajonc, R. B. (2000). Subliminal mere exposure: specific, general, and effects. Psychological Science, 11(6), 462-466.

Morris, J., \& Boone, M. (1998). The effects of music on emotional response, brand attitude, and purchase intent in an emotional advertising condition. In NA - Advances in Consumer Research Volume 25, eds. Joseph W. Alba \& J. Wesley Hutchinson, Provo, UT : Association for Consumer Research, Pages: 518-526.

Murphy, S. T., Monahan, J. L., \& Zajonc, R. B. (1995). Additivity of nonconscious affect: combined effects of priming and exposure. Journal of Personality and Social Psychology, 69(4), 589-602.

North, A., \& Hargreaves, D. (2008). The Social and Applied Psychology of Music. OUP Oxford.

Ohme, R., Reykowska, D., Wiener, D., \& Choromanska, A. (2009b). Analysis of 
neurophysiological reactions to advertising stimuli by means of EEG and galvanic skin response measures. Journal of Neuroscience, Psychology, and Economics, 2(1), 21-31.

Onton, J., Delorme, A., \& Makeig, S. (2005). Frontal midline EEG dynamics during working memory. NeuroImage, 27(2), 341-356.

Palva, S., \& Palva, J. M. (2007). New vistas for ??-frequency band oscillations. Trends in Neurosciences, 30(4), 150-158.

Robinson, T. N., Chen, H. L., \& Killen, J. D. (1998). Television and music video exposure and risk of adolescent alcohol use. Pediatrics, 102(5), e54.

Rossolatos, G. (2012). Applications, implications and limitations of the semiotic square for analyzing advertising discourse and discerning alternative brand futures. Signs International Journal of Semiotics, 6, 1-47.

Rothschild, M. L., Hyun, Y. J., Reeves, B., Thorson, E., \& Goldstein, R. (1988). Hemispherically lateralized EEG as a response to television commercials. Journal of Consumer Research, 15(2), 185-198.

Saner, E. (2016, June 1) Is M\&S right to scrap in-store music? The Guardian. Retrieved from https://www.theguardian.com/business/shortcuts/2016/jun/01/is-marks-and-spencerright-scrap-in-store-music

Sauseng, P., Klimesch, W., Gerloff, C., \& Hummel, F. C. (2009). Spontaneous locally restricted EEG alpha activity determines cortical excitability in the motor cortex. Neuropsychologia, 47(1), 284-288.

Savage, M. (2006). The musical field. Cultural trends, 15(2-3), 159-174.

Shams L., Iwaki S., Chawla A., \& Bhattacharya, J. (2005). Early modulation of visual cortex by sound. Neuroscience Letters, 378, 76-81.

Smith, E. E., Reznik, S. J., Stewart, J. L., \& Allen, J. J. B. (2017) Assessing and conceptualizing frontal EEG asymmetry: an updated primer on recording, processing, analyzing, and interpreting frontal alpha asymmetry. International Journal of 
Psychophysiology, 111, 98-114.

Solnais, C., Andreu-Perez, J., Sánchez-Fernández, J., \& Andréu-Abela, J. (2013). The contribution of neuroscience to consumer research: A conceptual framework and empirical review. Journal of Economic Psychology, 36, 68-81.

Szpunar, K. K., Schellenberg, E. G., \& Pliner, P. (2004). Liking and memory for musical stimuli as a function of exposure. Journal of Experimental Psychology. Learning, Memory, and Cognition, 30(2), 370-81.

Treasure, J. (2011) Sound Business. Management Books 2000 Ltd. Gloucestershire, UK.

Vecchiato, G., Astolfi, L., De Vico Fallani, F., Toppi, J., Aloise, F., Bez, F., ... Babiloni, F. (2011). On the Use of EEG or MEG brain imaging tools in neuromarketing research. Computational Intelligence and Neuroscience, 2011, Article ID 643489.

Vecchiato, G., Astolfi, L., Fallani, F. D. V., Cincotti, F., Mattia, D., Salinari, S., ... Babiloni, F. (2010). Changes in brain activity during the observation of TV commercials by using EEG, GSR and HR measurements. Brain Topography, 23(2), 165-179.

Vecchiato, G., Toppi, J., Maglione, A. G., Olejarczyk, E., Astolfi, L., Mattia, D., ... Babiloni, F. (2014). Neuroelectrical correlates of trustworthiness and dominance judgments. Computational and Mathematical Methods in Medicine, 2014, Article ID 434296.

Wang, R. W. Y., Chang, Y-C., \& Chuang, S-W. (2016) EEG spectral dynamics of video commercials: impact of the narrative on the branding product preference. Scientific Reports, 6, 36487.

Welch, P. (1967) The use of Fast Fourier Transform for the estimation of power spectra: a method based on time averaging over short, modified periodograms. IEEE Transactions on Audio and Electroacoustics, 15(2), 70-73.

Yang, T., Lee, D.-Y., Kwak, Y., Choi, J., Kim, C., \& Kim, S.-P. (2015). Evaluation of TV commercials using neurophysiological responses. Journal of Physiological Anthropology, 34(1), 19. 
Zajonc, R. (1980). Feeling and thinking: Preferences need no inferences. American Psychologist, 35 (2), 151-175.

Zajonc, R. B. (1968). Attitudinal effects of mere exposure. Journal of Personality and Social Psychology, 9 (2 pt 2), 1-27. 


\section{Figure Captions}

Figure 1. (a) Mean ratings on the liking of adverts; (b) Mean ratings on the familiarity of adverts; (c) Mean ratings on the liking of background music; (d) Mean ratings on the perceived fitness of background music to the brand in the advert. Error bars represent the standard error mean (s.e.m.). $* p<.05, * * p<.01, * * * p<.001$.

Figure 2. Beta and gamma band responses to the adverts: Beta (a) and gamma (e) band power at the global level for three types of radio adverts: adverts with strategic music (black), adverts with tactical music (gray), and adverts without any music (white). Spectral power was averaged across all electrodes. Error bars represent s.e.m.; Scalp maps of beta (b) and gamma (f) band power for radio adverts. Red colour indicates high power and blue indicates low power values; figures (c), (d), (g) and (h) represent the same as figures (a), (b), (e) and (f), respectively, but for TV adverts. * $p<.05$.

Figure 3. Instantaneous beta and gamma amplitudes over the frontal brain regions (values were averaged across the following electrodes: AF3/4, F7/8, F3/4, FC1/2, FC5/6) for the radio averts (upper panel) and TV adverts (lower panel). Within each panel, we showed two profiles, one for adverts with strategic music (thick line) and the other for adverts with tactical music (thin line). The horizontal broken black line represents the temporal windows for which statistical differences were observed between the two profiles (see Results). Figure 4. (a) Scalp maps of differences (strategic - tactical) in alpha band power. Difference values are expressed in percentages with regard to the power corresponding to the adverts with tactical music. Therefore, red regions indicate increase of alpha power and blue regions indicate decrease of alpha power for the strategic adverts; (b) Frontal alpha asymmetry values for the three types of adverts: adverts with strategic music (black), adverts with tactical music (gray) and adverts without any music (white). The left panel is for radio adverts and the right panel is for TV adverts. Error bars represent s.e.m. . ${ }^{*} p<.05$. 
Figure 5. (a) Behavioural responses to adverts divided in terms of musical genre (classical, modern and retro), media (radio and TV) and music (strategic and tactical). Four responses were shown as follows: liking of advert, familiarity of advert, liking of music, and perceived fitness of music to brand; (b) Gamma power for the three musical genres (classical, modern and retro) and the two types of music, strategic (black) and tactical (gray). The left panel is for radio adverts and the right panel is for TV adverts. Error bars represent s.e.m. . ${ }^{*} p<.05$, $* * p<.01, * * * p<.001$. 



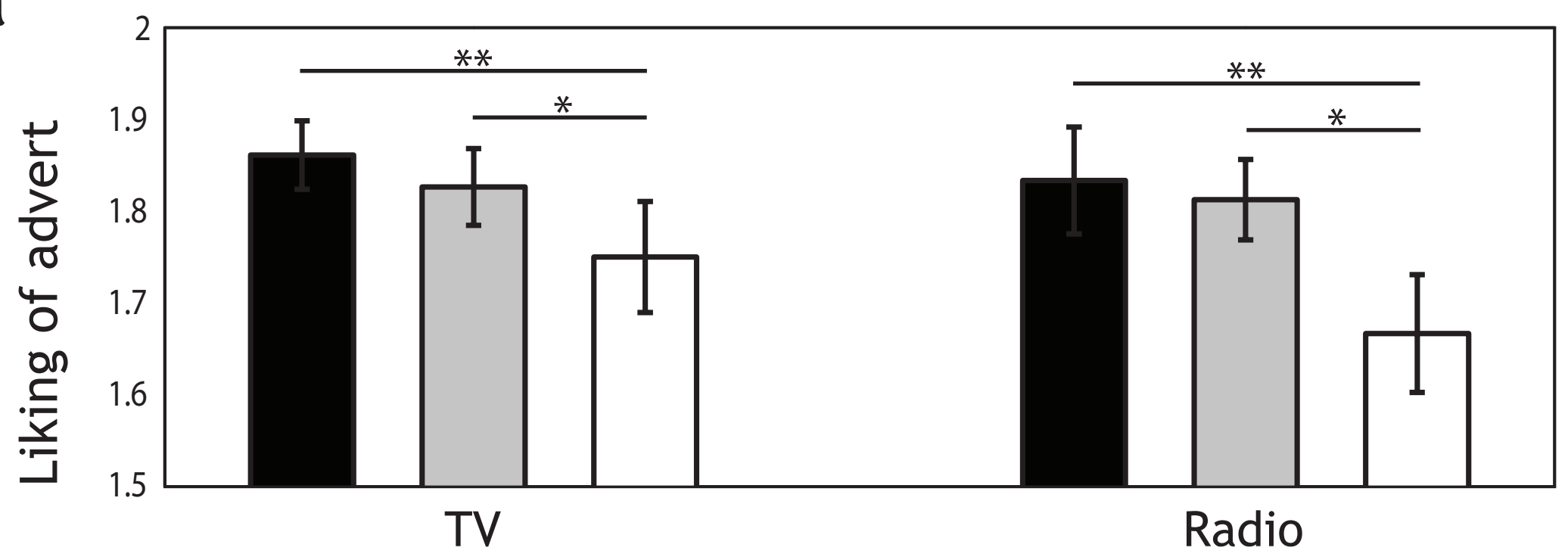

b

***

***
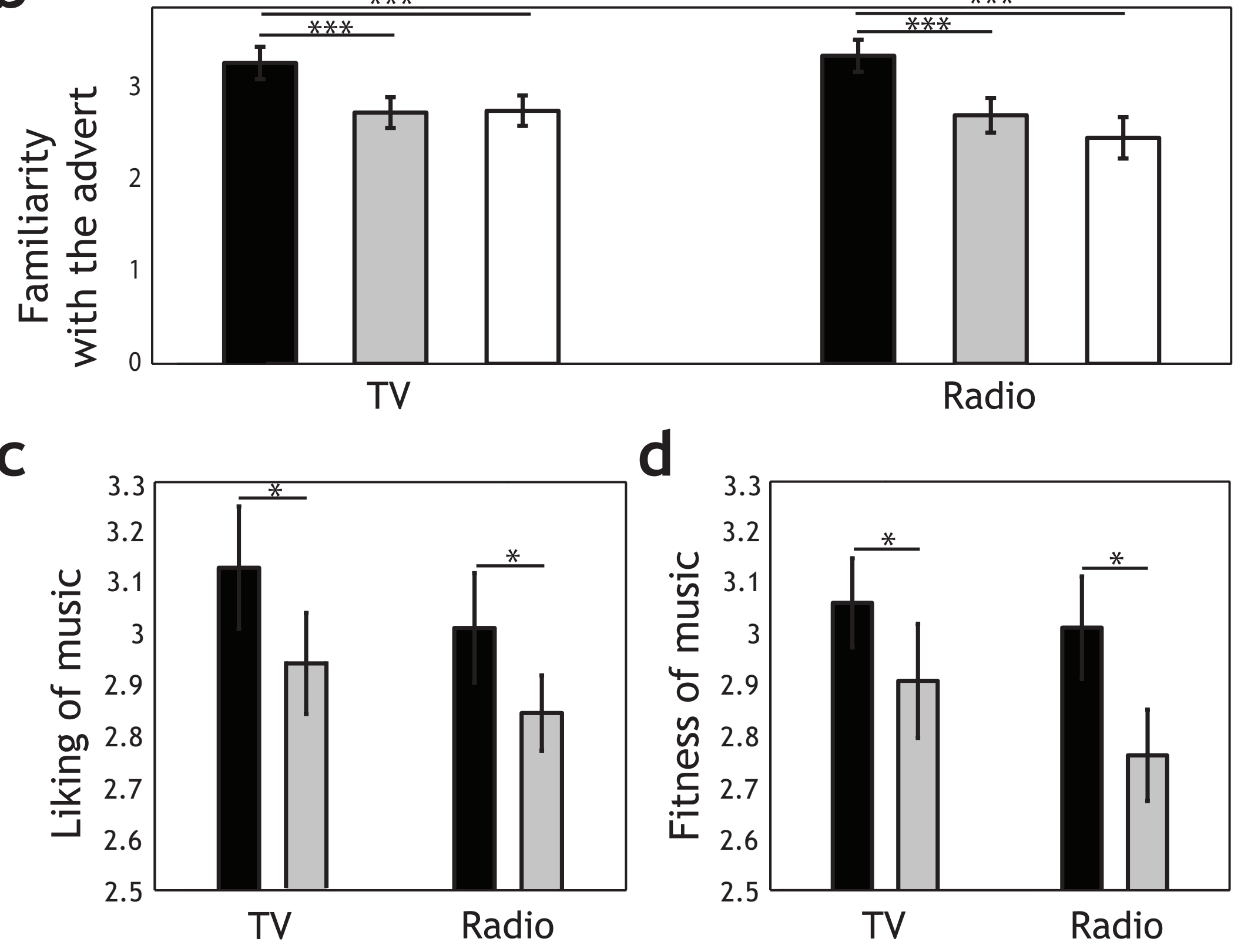

Strategic

Tactical

No music 


\section{Beta band (13-30 Hz) power}

a

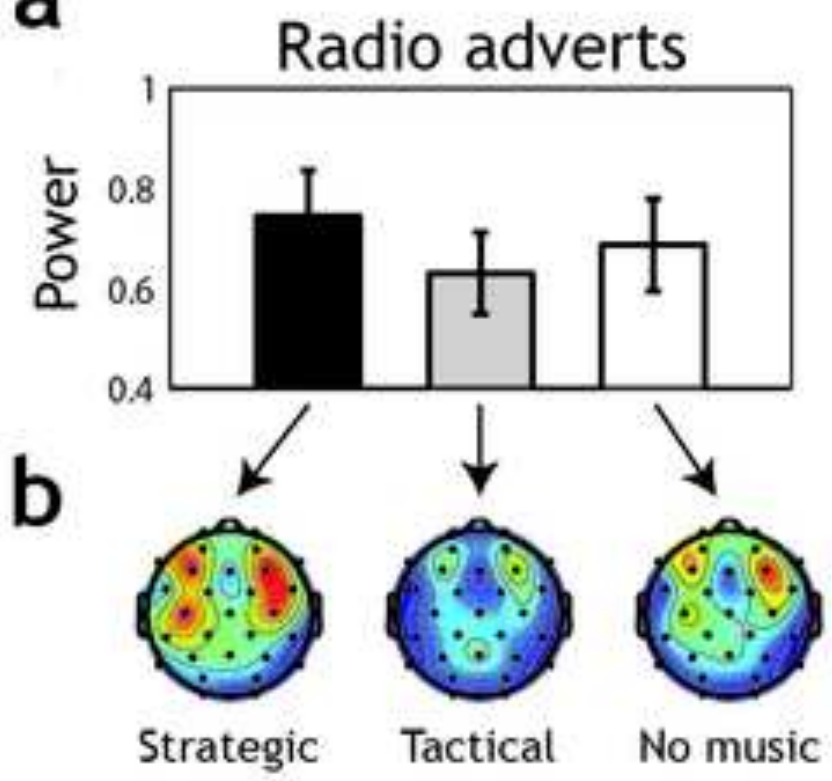

C

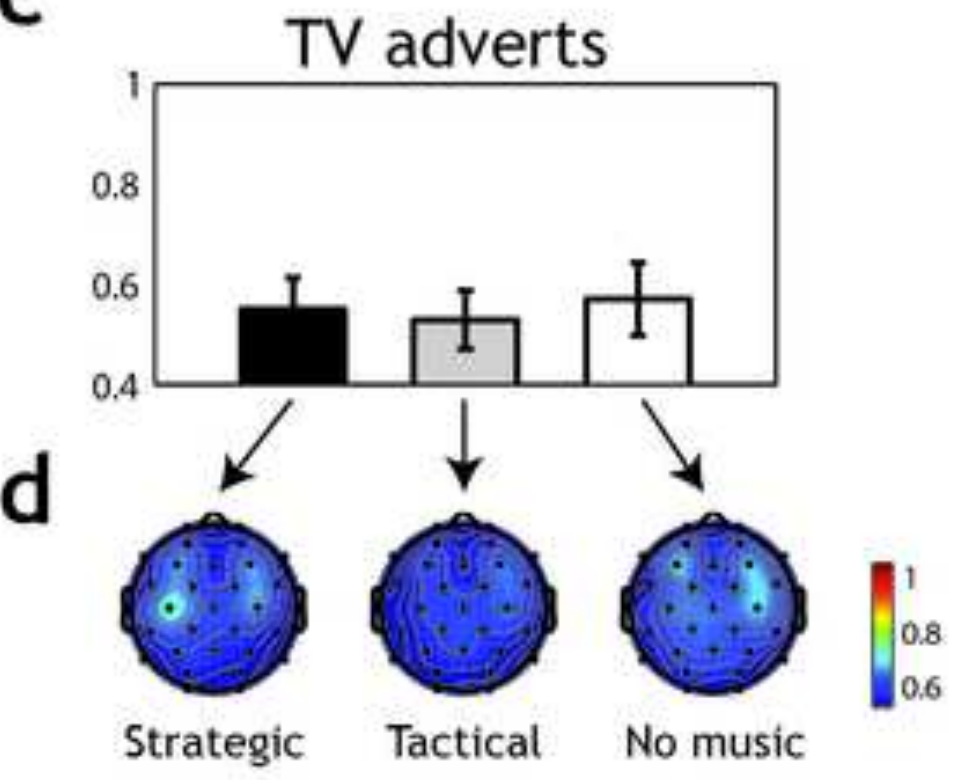

TV adverts

Gamma band $(30-48 \mathrm{~Hz})$ power

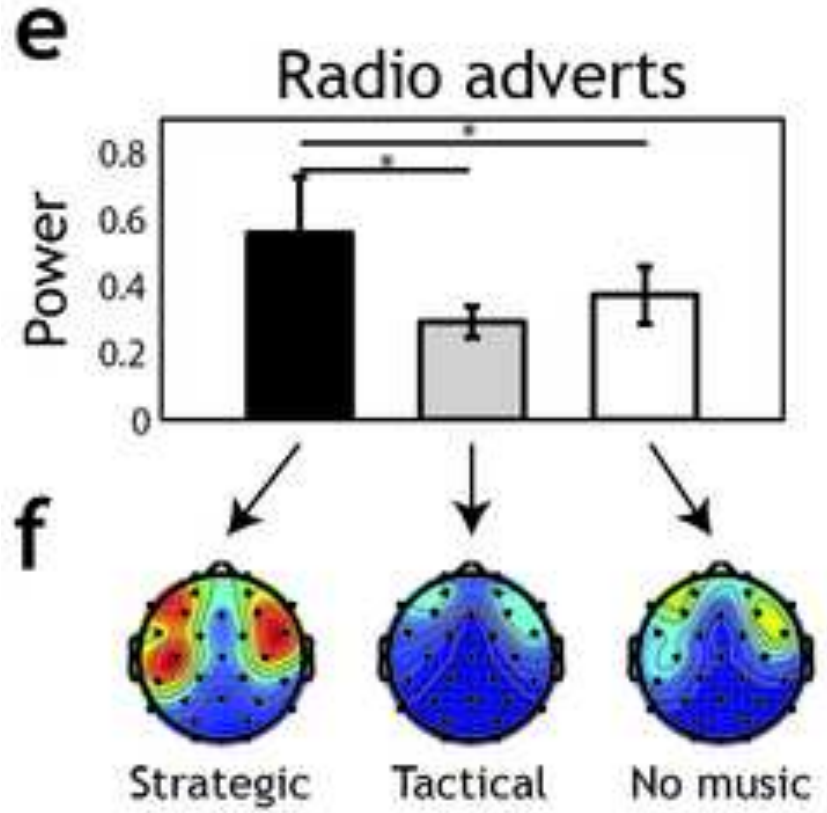

$\mathrm{g}$

TV adverts

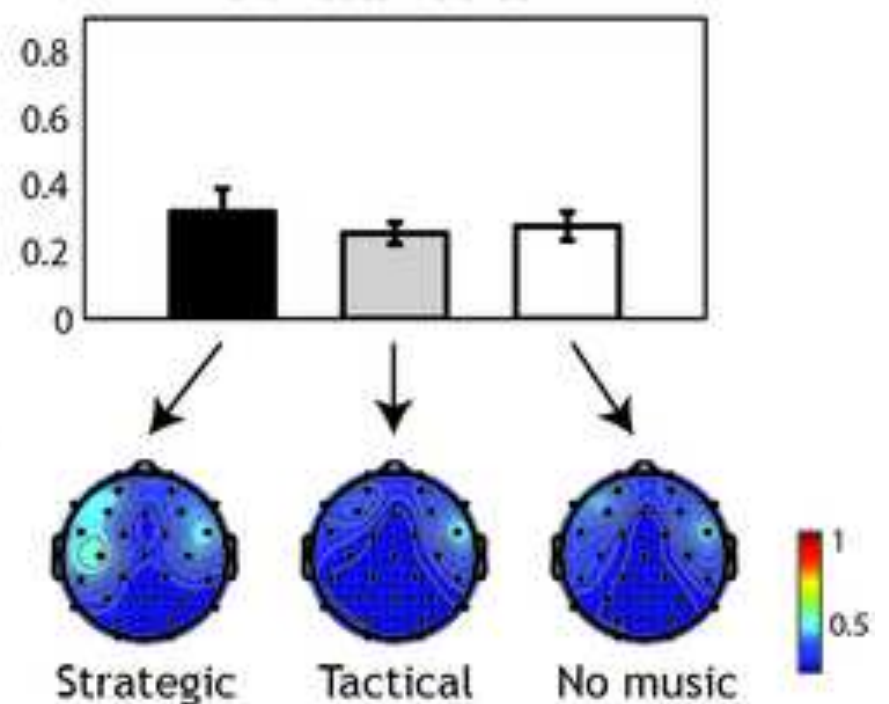

Strategic

Tactical

No music

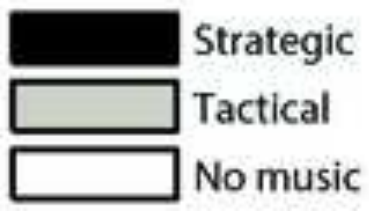


Radio adverts

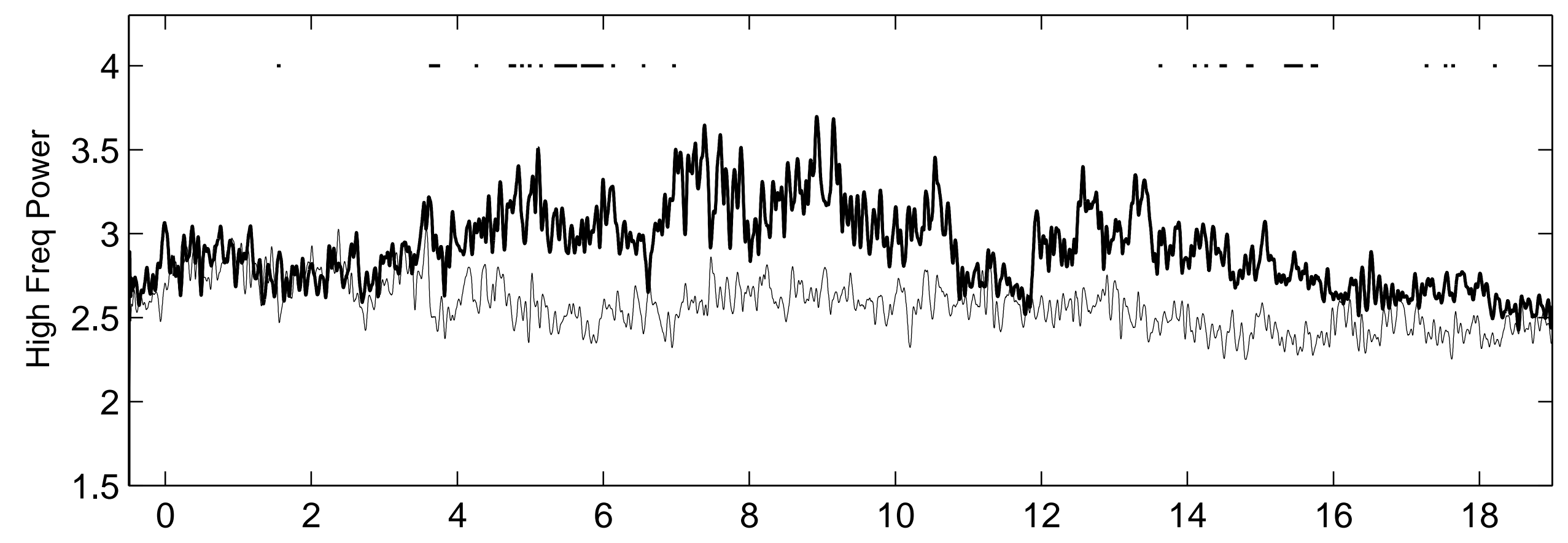

TV adverts

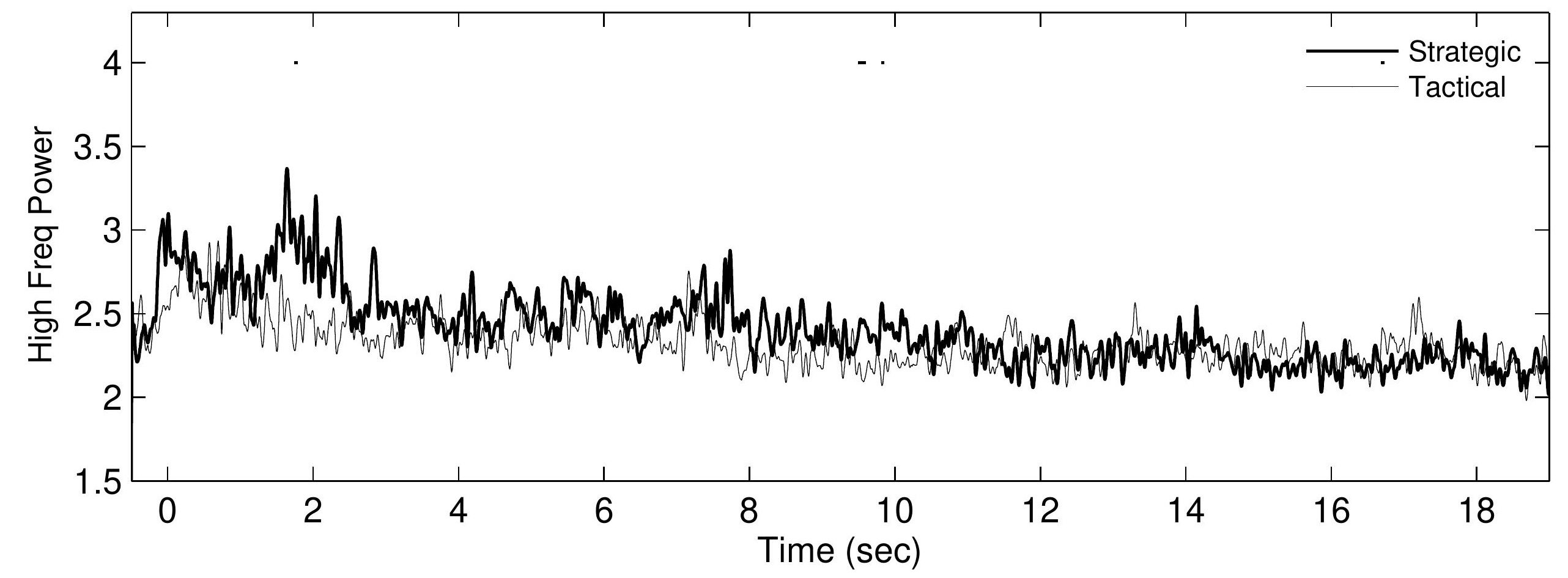




\section{Alpha band $(8-13 \mathrm{~Hz})$ power}

a
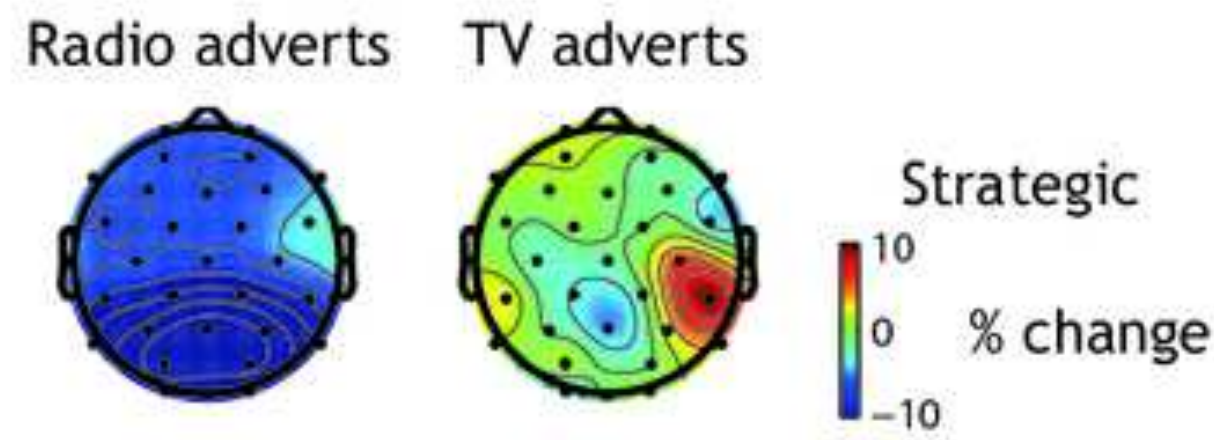

Tactical

b

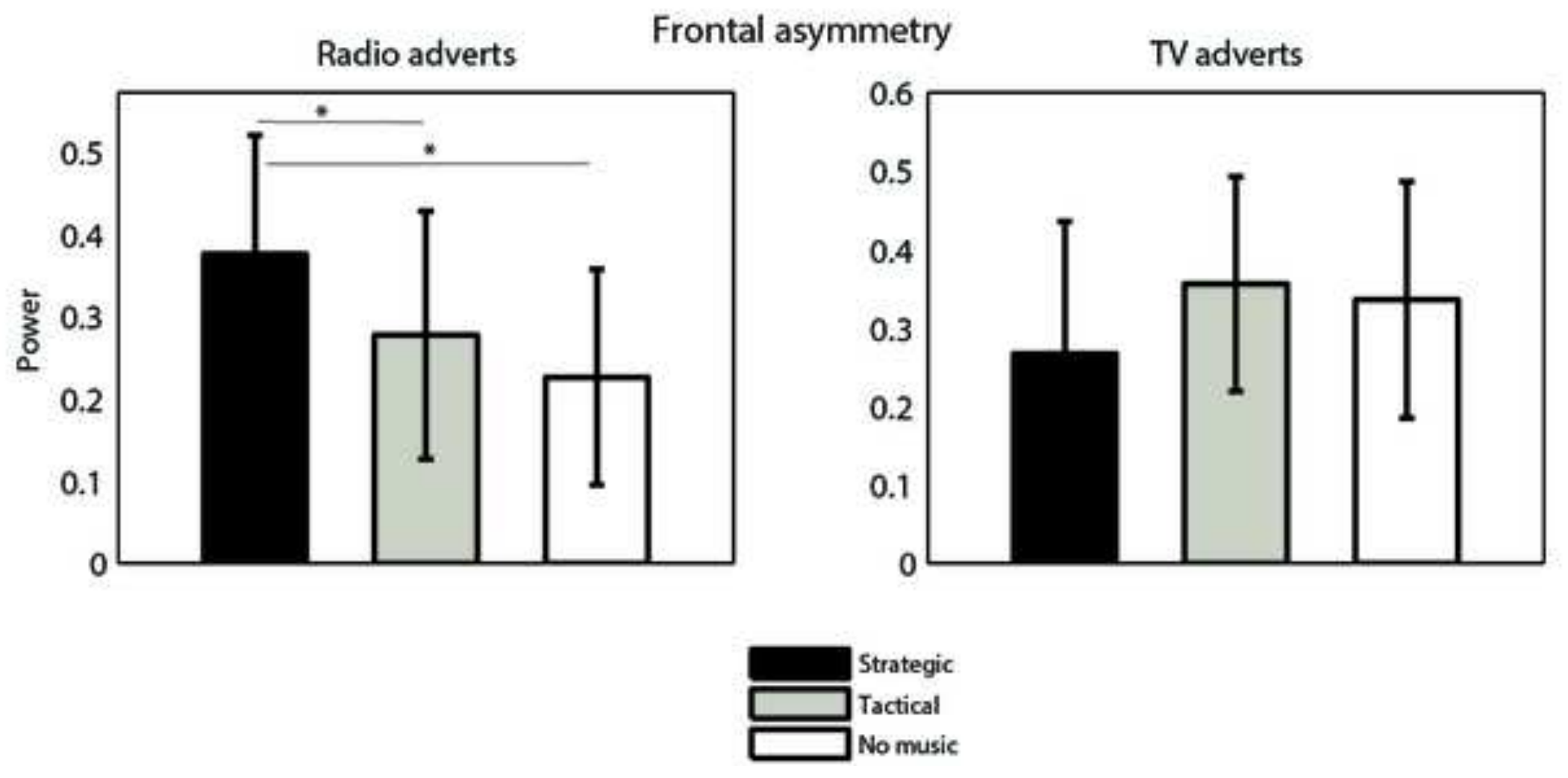


a
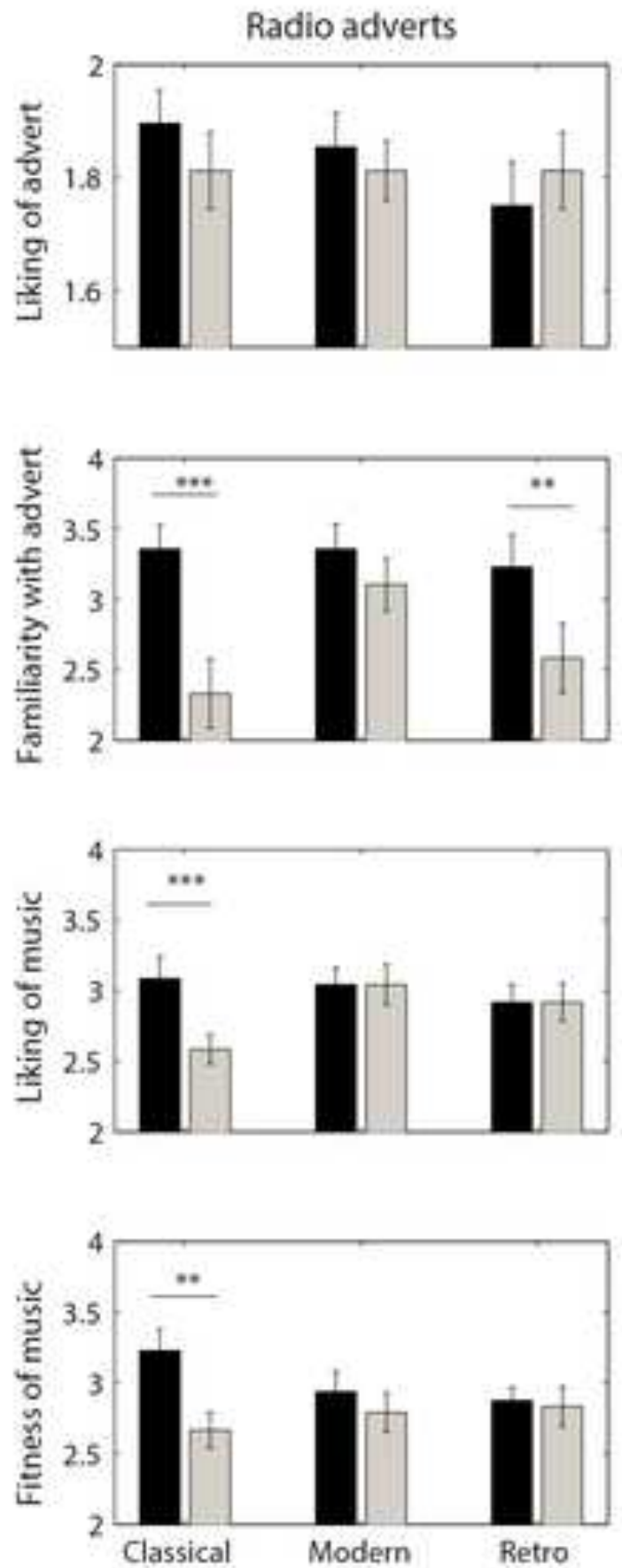

b

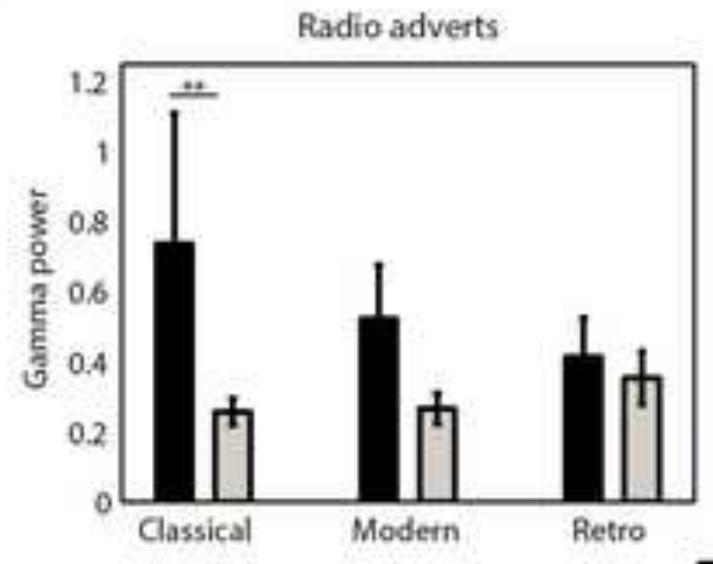

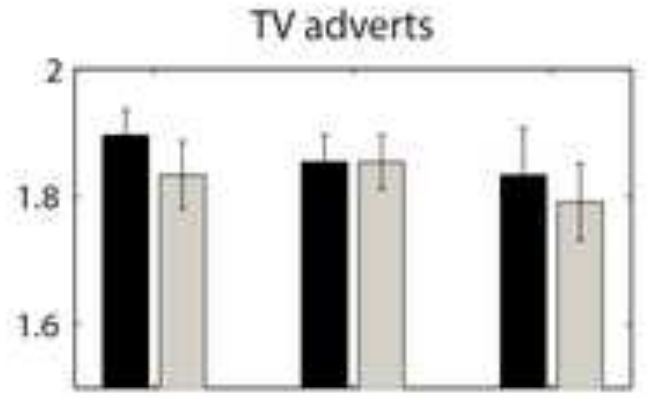
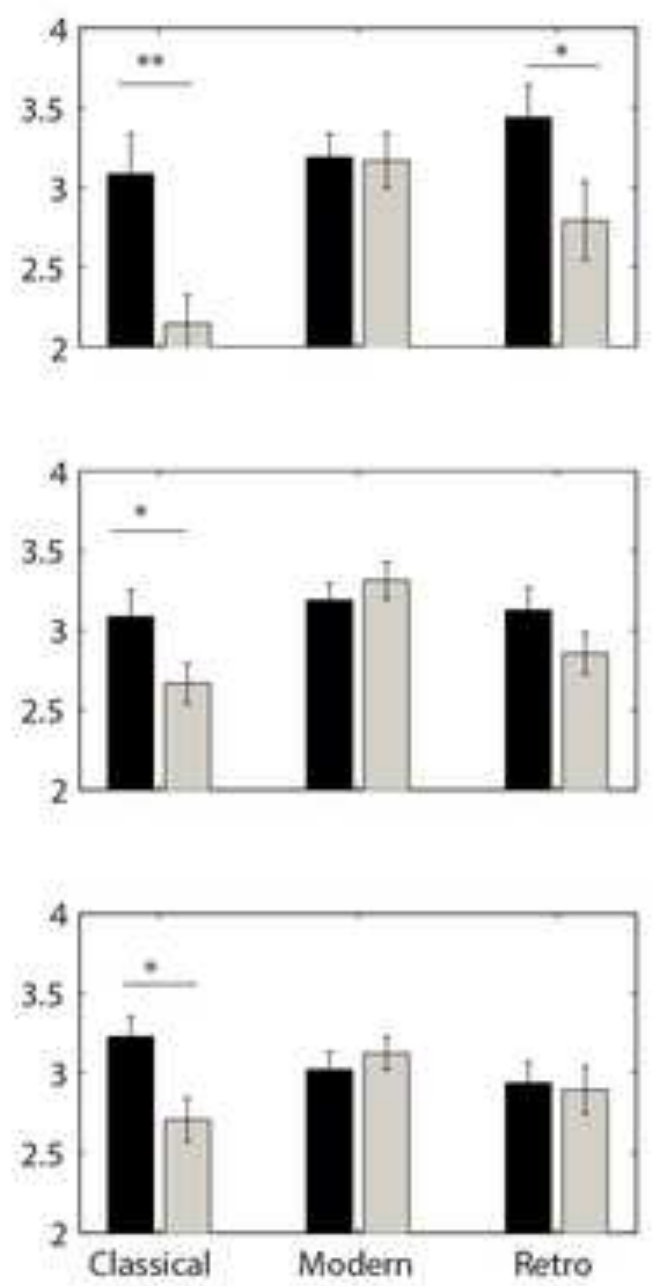

TV adverts

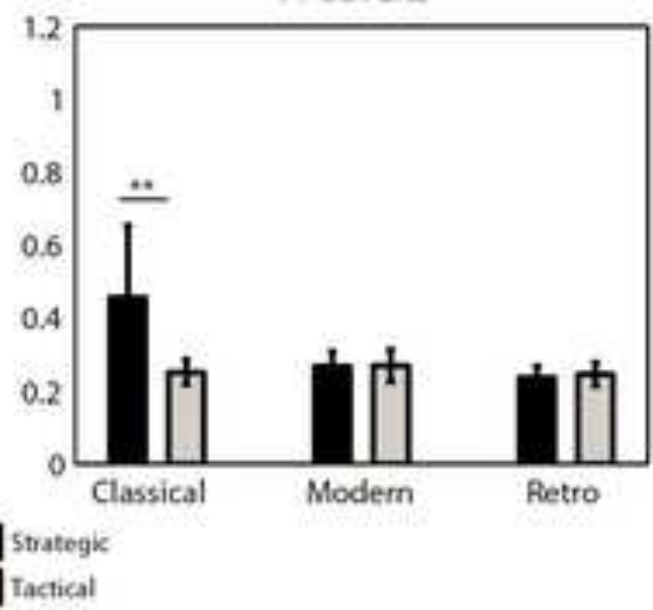


Table 1: List of presented adverts.

\begin{tabular}{|c|c|c|c|c|c|c|c|c|c|c|}
\hline \multirow[t]{2}{*}{$\begin{array}{l}\text { PRODUCT } \\
\text { SECTOR }\end{array}$} & \multicolumn{4}{|c|}{ STRATEGIC USE OF MUSIC } & \multicolumn{4}{|c|}{ TACTICAL USE OF MUSIC } & \multicolumn{2}{|l|}{ NO MUSIC } \\
\hline & Brand & Track listing & $\begin{array}{l}\text { Length } \\
\text { (sec) }\end{array}$ & $\begin{array}{l}\text { Date } \\
\text { first } \\
\text { used }\end{array}$ & Brand & Track listing & $\begin{array}{l}\text { Length } \\
\text { (sec) }\end{array}$ & $\begin{array}{l}\text { Date } \\
\text { first } \\
\text { used }\end{array}$ & Brand & $\begin{array}{c}\text { Length } \\
\text { (sec) }\end{array}$ \\
\hline Finance & Lloyds TSB & $\begin{array}{l}\text { Elena Kats-Chernin, } \\
\text { Eliza's Aria, from Wild } \\
\text { Swans ballet }\end{array}$ & 40 & 2007 & Natwest & $\begin{array}{l}\text { Jon Brion, Eternal } \\
\text { sunshine for the } \\
\text { spotless mind piano } \\
\text { solo }\end{array}$ & 40 & 2013 & Mastercard & 30 \\
\hline \multirow[t]{2}{*}{ Food/drink } & Diet Coke & $\begin{array}{l}\text { Etta James, I just } \\
\text { wanna make love to } \\
\text { you }\end{array}$ & 20 & 1996 & Shreddies & $\begin{array}{l}\text { Mitch Miller Chorus: } \\
\text { Soundtrack to 'The } \\
\text { longest day' (end } \\
\text { theme) }\end{array}$ & 30 & 2014 & John West Tuna & 30 \\
\hline & Twinings & $\begin{array}{l}\text { Charlene Soraia, } \\
\text { Wherever You Will Go }\end{array}$ & 20 & 2011 & Muller Rice & $\begin{array}{l}\text { Vanilla Ice, Ice Ice } \\
\text { Baby }\end{array}$ & 20 & 2013 & Lurpack & 40 \\
\hline Gov/info & $\begin{array}{l}\text { HMRC tax } \\
\text { credits }\end{array}$ & $\begin{array}{l}\text { Re-record of The } \\
\text { Upsetters, Return of } \\
\text { Django }\end{array}$ & 20 & 2006 & $\begin{array}{l}\text { DCMS } \\
\text { Superfast } \\
\text { Broadband }\end{array}$ & $\begin{array}{l}\text { The Who, Won't get } \\
\text { fooled again }\end{array}$ & 30 & 2014 & DWP - Benefit Thieves & 30 \\
\hline $\begin{array}{l}\text { Household } \\
\text { products }\end{array}$ & Karcher & $\begin{array}{l}\text { Fats Waller, Spring } \\
\text { cleaning }\end{array}$ & 30 & 2010 & Dulux & Composed for Dulux & 30 & 2015 & Domestos & 30 \\
\hline \multirow[t]{2}{*}{ Retail } & $\mathrm{B} \& \mathrm{Q}$ & Snap!, The Power & 30 & 2014 & Next & $\begin{array}{l}\text { Vampire Weekend, A- } \\
\text { Punk }\end{array}$ & 30 & 2011 & $\mathrm{LiDL}$ & 30 \\
\hline & Homebase & $\begin{array}{l}\text { Peter, Bjorn \& John, } \\
\text { Young Folks }\end{array}$ & 10 & 2009 & $\mathrm{M} \& \mathrm{~S}$ & Ed Sheeran, Sing & 30 & 2014 & PC World & 30 \\
\hline Travel & $\begin{array}{l}\text { British } \\
\text { Airways }\end{array}$ & Lakme, Flower Duet & 30 & 1989 & Monarch & $\begin{array}{l}\text { Composed for Monarch } \\
\text { airlines }\end{array}$ & 30 & 2014 & Hotels.com & 30 \\
\hline Utilities/services & British Gas & Blur, The Universal & 30 & 2009 & Total jobs & $\begin{array}{l}\text { Composed for Total } \\
\text { Jobs }\end{array}$ & 30 & 2014 & Npower & 30 \\
\hline
\end{tabular}

